RU Изменение звуковой оболочки слова как фактор лингвистической идентичности (на материале немецкого и русского языков)

\author{
Жаркова У. А.
}

\begin{abstract}
Аннотация. Цель исследования - выявление особенностей интерференции на фонетическом уровне при освоении иностранного языка в индивидуальном и коллективном языковом сознании. Научная новизна исследования состоит в том, что в статье впервые устанавливаются корреляции между традициями фонетической адаптации заимствований из немецкого языка в русский язык и точками сбоя аутентичности при освоении звукового строя немецкого языка как иностранного. В результате исследования установлена роль единиц фонетического уровня языка в формировании лингвистической идентичности, описано влияние разных типов фонетических трансформаций заимствований из немецкого языка в русский язык на появление фонетических ошибок.
\end{abstract}

\title{
Change of Word Sound Shell as Factor of Linguistic Identity (by the Material of the German and Russian Languages)
}

\author{
Zharkova U. A.
}

\begin{abstract}
The paper aims to reveal interference peculiarities at the phonetic level while mastering a foreign language in individual and collective linguistic consciousness. Scientific originality of the study lies in the fact that the author for the first time ascertains correlations between traditions of phonetic adaptation of borrowings from German into Russian and authenticity failures while mastering phonetics of the German language as a foreign one. The research findings are as follows: the author has determined phonetic units role in linguistic identity formation, described influence of different types of phonetic transformations of borrowings from German into Russian on phonetic mistakes appearance.
\end{abstract}

\section{Введение}

Межкультурная коммуникация создает в поле современных научных исследований языка и культуры контекст, в рамках которого множество лингвистических теорий оказываются культурно детерминированными и обращаются к изучению предметов заведомо интегративного, гетерогенного характера, таких как идентичность. Актуальность настоящего исследования обусловлена возрастающим интересом ученых-лингвистов к факторам формирования и трансформации лингвокультурной и лингвистической идентичности индивида в эпоху активизации миграционных процессов, а также к расширению лингвокультурологического потенциала некоторых терминов, в частности интерференции. Труды об освоении таких аспектов иностранного языка, как фонетика и грамматика, в свете теории межкультурной коммуникации не сформировали значительного пласта в отечественном языкознании, в то время как языковая ошибка является наиболее очевидным, в большинстве случаев не нуждающимся в (часто субъективной) интерпретации маркером сбоя лингвокультурной идентификации.

Звуковая оболочка языковых единиц рассматривается в лингвистике как материальная основа таковых. Реализуясь посредством акустически реальных артикулируемых звуков речи, звуковая оболочка как инвариант воплощается во множестве вариантов произнесения, детерминируемых не только индивидуальными особенностями речевого аппарата говорящего, но и артикуляционной базой того или иного языка. Инвариантность в данном случае обеспечивает возможность идентификации единицы - прежде всего слова в единстве его формы и содержания, следовательно, взаимопонимания в процессе коммуникации, в то время как вариативность артикуляции на сегментном и супрасегментном уровнях (звуки - ударение - интонация) тесно связана с нормативностью произношения. Лингвистическая самоидентификация сопряжена с аутентичностью

Научная статья (original research article) । https://doi.org/10.30853/phil210091

(๔ 2021 Авторы. ООО Издательство «Грамота» (๔ 2021 The Authors. GRAMOTA Publishers). Открытый доступ предоставляется на условиях лицензии СС ВY 4.0 (open access article under the CС BY 4.0 license): https://creativecommons.org/licenses/by/4.0/ 
произношения: стремясь избавиться от акцента, говорящий на иностранном языке пытается приблизиться к определению себя как носителя данного языка. Таким образом, материальное воплощение звуковой оболочки становится фактором самоидентификации.

Поставленная цель повлекла за собой необходимость решения следующих исследовательских задач: выявление сущности лингвокультурной идентичности и роли интерференции единиц фонетического уровня языка в лингвокультурной идентификации индивида и коллектива; анализ различий в артикуляционных базах немецкого и русского языков для установления точек сбоя в аутентичности речевой деятельности на немецком языке как иностранном; классификация типов фонетических трансформаций немецкоязычных заимствований в русском языке и установление корреляции между фонетическими/фонематическими ошибками и традициями фонетической адаптации в индивидуальном и коллективном языковом сознании.

В работе использовались следующие методы исследования: метод лингвистического анализа, описательноаналитический метод, сопоставительный анализ, метод классификации.

Теоретическая база исследования: труды по теории межкультурной коммуникации и феномену идентичности Г. М. Вишневской, Н. Ф. Герман, В. В. Красных, М. А. Лаппо, исследования межъязыковой интерференции в трудах Ж. Багана и Е. В. Хапилиной, Е. А. Будник, А. И. Николаева, С. Е. Перепечкиной и др., а также работы по трансформации языковых единиц в результате заимствования Р. М. Ефимовой, Г. Г. Тазеева и др.

Практическая значимость исследования состоит в том, что сделанные выводы относительно корреляции элементов акцента и традиций фонетических трансформаций при заимствовании могут быть использованы в практике преподавания немецкого языка носителям русского языка во вводно-фонетическом курсе.

\section{Лингвистическая идентичность и языковая норма}

Лингвокультурная идентичность как понятие, возникшее на стыке собственно лингвистических и культурологических исследований, представляет собой концепт, позволяющий взглянуть на языковые единицы и явления с точки зрения межкультурной коммуникации и межъязыкового общения. Понимание лингвокультуры как «оязыковленной» культуры, а описание лингвокультурной идентичности как владения правилами кодирования и декодирования знаков данного языка в качестве знаков той или иной культуры обязывает нас в рамках лингвистического исследования оставаться на высоте когнитивной, метафорической, символьной и эталонной субсистем культуры [7]. Бесспорно взаимовлияние этнического, социокультурного, личностного, группового и лингвокультурного видов идентичности [9]. Как правило, когда лингвисты говорят о лингвокультурной или лингвистической идентичности, речь идет о представлениях и ценностях, тезаурусе, концептах и дискурсе [4; 6-8]. Мы предлагаем рассматривать собственно лингвистическую идентичность (я - носитель языка) в качестве основы для лингвокультурной идентичности (я - носитель лингвокультуры), и тогда в поле зрения лингвиста попадает не только семантический и прагматический уровни языкового анализа, но и фонетические и грамматические единицы языка. Действительно, если ошибка в кодировании и декодировании смыслов может привести к сбою в межкультурной коммуникации [4], в основе которого - распознавание и неприятие чужеродного элемента, то правомерным будет считать фактором риска языковые и речевые, фонематические и фонетические ошибки в речи на иностранном языке, ведь именно их наличие позволяет идентифицировать партнера по коммуникации как «чужого». Степень владения иностранным языком билингва - индивида, владеющего родным и как минимум одним иностранным языком, - в таком случае может подвергнуться шкалированной оценке и вызывать разного рода эмоционально-психологические реакции у участников коммуникации. Постоянным признаком речи человека, не владеющего данным языком как родным, является иноязычный акцент, он «маркирует» говорящего как иностранца, «чужого». Реакцию носителя языка на акцентную речь билингва можно условно расположить на шкале, крайние точки которой характеризуются в терминах: «сильный/слабый акцент», «неприятный/приятный акцент». Та или иная характеристика акцента, данная носителем языка, основывается на его языковом и социальном опыте и носит поэтому достаточно субъективный характер. Многие ученые признают, что добиться «безакцентного произношения» в ситуации искусственного билингвизма практически невозможно, но стоит стремиться к тому, чтобы произношение говорящего на неродном языке было допустимым с точки зрения носителя языка. Поэтому необходимо исправлять и предупреждать именно те фонетические ошибки в речи обучающихся, которые мешают достижению эффективности речевого общения [3].

С точки зрения лингвистической самоидентификации билингва можно также говорить о степени владения нормой изучаемого языка. Ведь часто именно акцент является причиной языкового барьера в ситуации, когда не только носители языка сталкиваются с проблемой понимания речи мигрантов, но и сами мигранты из разных стран, общаясь между собой, должны уметь, с одной стороны, бороться с акцентом в своей речи, с другой - игнорировать фонетические ошибки и неточности в речи других людей, чтобы лучше их понять. Если обратить внимание обучающихся на то, что приспособление слов к «родному» произношению - неизбежный процесс, показать это на примере заимствований, то процесс самоидентификации будет проходить более комфортно и продуктивно.

Борьба с акцентом может начаться прежде всего с осознания того, по каким причинам он возникает, как происходит изменение звуковой оболочки слова. Изучение фонетических трансформаций заимствований и анализ отличий артикуляционных баз немецкого и русского языков позволят прогнозировать особенности акцента и эффективно их исправить. 


\section{Явление интерференции и феномен иноязычного акцента}

В современных исследованиях все большую актуальность приобретает взаимодействие разных языковых систем: одной из наиболее активно изучаемых проблем является двуязычие, или билингвизм, а также механизмы интерференции [Там же]. Под интерференцией понимают процесс, обусловливающий смешение элементов родного и изучаемого языков в лингвистическом сознании индивидуума вследствие наложения двух систем при языковом контакте [Там же]. Изучение интерференции проводится как на уровне сопоставительного структурно-лингвистического анализа, так и на уровне ее результатов - иноязычного акцента и фонетических ошибок $[1 ; 2 ; 10 ; 11]$. Интерференция зависит от субъективных и объективных факторов, таких как языковые способности говорящего и степень сходства взаимовлияющих языков. Таким образом, учить сходные языки проще, но избежать интерференции сложнее [1].

Акцент считается результатом интерференции - ошибки в речи говорящего, которые воспринимаются носителем языка как отклонения от нормы, характеризующиеся определенной спецификой, отражающей национально-языковую принадлежность говорящего [3]. Еще Л. В. Щерба создал ценную теорию о двух типах произносительных ошибок - фонетических (ошибок выговора) и фонологических (звукосмысловых) на сегментном уровне. Первые искажают качество звучания, но не нарушают смысла высказывания, они, по выражению Л. В. Щербы, создают карикатурность речи [Там же]. Ошибки второго типа искажают содержание высказывания.

По утверждению Е. А. Будник, фонетическая интерференция обнаруживает закономерности, характерные для представителей определенной языковой общности, иначе говоря, подавляющее большинство англичан, говорящих на русском языке, допускают типичные ошибки [2]. В. В. Виноградов обращал внимание на целесообразность разграничения двух типов иноязычного акцента - «преходящий» акцент, возникающий на этапе овладения языком, и «остаточный» акцент, свойственный стадии владения вторым языком [10]. Доказано, что «остаточный акцент» проявляется главным образом в интонации и сохраняется даже при высокой степени владения неродным языком [3]. Системность и предсказуемость фонетических нарушений речи на неродном языке делают возможным устранение ошибок при сознательной опоре на родной язык (прогнозирование акцента) [2].

Несмотря на то, что устройство речевого аппарата у всех людей одинаковое, очевидно, что аутентичное произношение для каждого языка разное. Артикуляционная база очень устойчива и привычна для всех членов данного языкового коллектива. Перенесение артикуляционной базы одного языка на произношение звуков другого языка и дает так называемый акцент.

Результаты сопоставления артикуляционных баз русского и немецкого языков позволяют прогнозировать некоторые аспекты акцента. Для носителя русского языка, вероятно, будет сложно различать гласные по долготе-краткости и избегать удлинения гласных в ударном слоге, избегать смягчения согласных, произносить звуки с опущенной гортанью, произносить двухкомпонентные слова с двумя ударениями, произносить гласные с твердым приступом в начале слова или слога, произносить согласные полузвонко, оглушать согласные в конце слова или слога, произносить смычные глухие согласные с придыханием.

Наиболее очевидной сложностью являются случаи несовпадения фонемного состава языков.

\begin{tabular}{|c|c|}
\hline \multicolumn{2}{|c|}{ Звуки, отсутствующие } \\
\hline в немецком языке & в русском языке \\
\hline ы, мягкие согласные & $\mathrm{y}, \emptyset, \mathrm{g}, \mathrm{h}$ \\
\hline
\end{tabular}

Также, как уже говорилось, есть звуки, которые имеют аналоги в других языках, но произносятся с разными артикуляционными характеристиками, например:

[P] в русском языке - переднеязычный, a [R] в немецком - увулярный;

[Ч] в русском языке - мягкий звук, [t $\mathrm{t}]$ - твердый;

[л] в русском языке различается по мягкости-твердости, [1] в немецком языке - переднеязычно-альвеолярный звук.

Итак, сопоставление фонетических и артикуляционных баз немецкого и русского языков позволяет предположить, какие именно особенности произношения могут привести к акценту в иноязычной речи.

\section{Фонетические трансформации заимствований}

С изменением звуковой оболочки слова мы имеем дело также при заимствованиях словарного состава. Исходя из того, что заимствование затрагивает различные языковые уровни - фонологию, морфологию, лексику, синтаксис, семантику, - лингвисты выделяют, соответственно, и различные уровни заимствования. Иноязычные лексические единицы подвергаются фонетико-графическому, морфологическому и семантическому освоению в системе заимствующего языка [5]. Законы, лежащие в основе трансформации звуковой оболочки слова в историческом аспекте, были предметом исследования классиков отечественной лингвистики [12]. Мы исходим из того, что фонетическая адаптация заимствованных слов - возможно, первый шаг в присвоении языком нового слова. То, что заимствованные слова подвергаются существенной фонетической трансформации - на них переносятся особенности артикуляционной базы языка-реципиента, - наводит на мысль, что звуковая оболочка языковой единицы неустойчива и разрушается при употреблении слова иностранцем. 
Рассмотрим основные механизмы фонетических трансформаций немецких слов в русском языке - в заимствованиях и в русской речи.

Мы выделяем следующие группы фонетических изменений в заимствованиях.

1. Артикуляционная адаптация при совпадении фонемного состава.

В таких заимствованиях сохраняются все звуки исходного слова, а также его ударение. Немецкие звуки, имеющие эквиваленты в русской артикуляционной базе, заменяются русскими. К этой группе относятся слова:

Mops - мопс; Kitsch - китч (звук [k] потерял придыхание, аффриката [t]] стала мягкой); Platz - плац (звук [л] произносится как переднеязычно-зубной, а не переднеязычно-альвеолярный, как в немецком языке); Schrift шрифт (звук [r] произносится не как язычковый, а как переднеязычный дрожащий, звук [t] теряет придыхание).

Такие слова имеют минимальное отличие от языка-оригинала.

2. Звуковая адаптация.

В таких заимствованиях звуки, которых нет в русском языке, заменяются на схожие. Либо, если звук даже есть в русском языке, эта фонетическая позиция для него нехарактерна, в связи с чем звук заменяется на другой: дифтонги [ае], [ое]: Leutnant - лейтенант, Zeitnot - цейтнот, Großmeister - гроссмейстер, Bürgermeister бургомистр, Feuerwerk - фейерверк, Leitmotiv - лейтмотив;

звук [h] в начале слова на [г]: Hauptwache - гауптвахта, Halstuch - галстук, Hantel - гантель; звуки [у], [ø]: Flügel - флигель, Mundstück - мундштук;

замена звуков по твердости-мягкости: Strich - штрих, Schicht - шихта, Rucksack - рюкзак;

замена звуков по звонкости-глухости: Humanismus - гуманизм, Schlagbaum - шлагбаум;

замена звука [1] на мягкий или твердый [л]: Zirkel - циркуль, Feldfebel - фельдфебель, Sockel - цоколь, Walzer вальс, Schlange - шланг, Schlagbaum - шлагбаум, Zifferblatt - циферблат, Landschaft - ландшафт;

замена вокализованного [в] на четко звучащий звук [р] в конце слова: Feldscher - фельдшер, Jäger - егерь, Büsthalter - бюстгальтер.

И другие единичные случаи адаптации звуков:

Losung - лозунг (замена несуществующего в русском языке звука [р] в конце слова на соответствующее буквенному написанию сочетание [нг]), Kachel - кафель, Flasche - фляжка, Sockel - цоколь.

3. Количественная и качественная замена звукового состава слова.

В таких заимствованиях происходит не замена одного звука на другой, а либо изменение количества звуков (удаление или добавление звука в конце слова):

Schlange - шланг, Marschroute - маршрут, Adresse - адрес, Schacht - шахта, Schleife - шлейф, Strecke штрек,

либо русский язык приспосабливает немецкое слово к более удобному для него звучанию не только фонетически, но и морфологически:

Durchschlag - дуршлаг, Jahrmarkt - ярмарка, Waffel - вафля, Frikadelle - фрикаделька, Flasche - фляжка, Werkstatt - верстак.

Существует также особый вид качественно-количественной адаптации, в которой задействован твердый приступ. Так, слова «курорт», «почтамт» в русском языке не воспринимаются как делимые на два корня и делятся по слогам ку-рорт, по-чтамт, в то время как в немецком языке исходные слова делятся на два корня и второй корень произносится с твердым приступом Kur-'ort, Post-'amt.

4. Замена ударения.

В большинстве случаев при адаптации немецкого двухкорневого слова в русском языке ударение перемещается на вторую часть:

Schlagbaum - шлагбаум, Riesenschnauzer - ризеншнауцер.

Кроме того, ударение смещается с ударной приставки на корень, например:

Vorpost - форпост, Absatz - абзац, Anschlag - аншлаг.

Таким образом, мы можем выделить склонность русского человека, говорящего на немецком языке, к следующим особенностям произношения (и именно эти ошибки могут привести к акценту):

- перемещение ударения в сложных словах с первого корня на второй или с приставки на корень;

- четкое произнесение звука [r] в конце слова или слога;

- озвончение глухих согласных в конце слова в соседстве со звонкими согласными;

- замена звуков, не имеющих аналогов в русском языке (дифтонги, звуки [h] [у] [ø] и др.), на звуки родного языка;

- отсутствие твердого приступа;

- искажение твердости-мягкости согласных, особенно согласного [1].

Мы видим, что сопоставление фонетических и артикуляционных баз немецкого и русского языков, а также анализ фонетических оболочек заимствованных слов приводит к схожим выводам. Обратим внимание, что результаты наблюдения за изучающими немецкий язык в рамках отдельного вводно-фонетического курса позволяют утверждать, что в вышеприведенном списке маркеры русского акцента в речи на немецком языке как иностранном расположены по степени длительности их присутствия в речи. Очевидно, что большое влияние на фонетические ошибки оказывает традиция заимствования с переносом ударения в производных и сложных словах, а также традиции звуко-буквенных соответствий - чем больше звуковая оболочка слова не соответствует буквенному обозначению (например, в случае редукции, вокализации, аспирации, твердого приступа), тем более вероятна ошибка. В частности, произнесение слов Schlagbaum и Durchschlag с ударением 
на втором корне является следствием интерференции формы данных заимствований в системе русского лексикона и ошибкой с точки зрения произносительной нормы немецкого языка, а значит, элементом акцента. Формы глагола tanze и tanzen представляют собой единицы с разным провокативным потенциалом - в то время как в первой форме, опираясь на буквенное обозначение, можно произнести слово без фонетических ошибок, во второй форме говорящий, не владеющий нормой произношения немецкого языка, в стремлении «озвучить» все буквы, реализует окончание -еп в полной форме, без полной элиминации звука [ə] и без придания звуку [n] слогообразующего характера, что не является ошибкой, но представляет собой отклонение от аутентичной произносительной нормы немецкого языка, то есть также формирует иноязычный акцент при говорении на немецком языке как иностранном.

Таким образом, несоответствие артикуляционных баз двух языков - русского и немецкого - обусловливает трансформации слов при заимствовании, а также приводит к акценту - произносительным искажениям слов в иноязычной речи. При этом механизмы трансформации заимствований и произносительных ошибок сходны.

\section{Заключение}

В результате исследования мы приходим к следующим выводам.

Основой для лингвокультурной идентичности является собственно лингвистическая идентичность, под которой мы понимаем результат шкалированного отождествления себя с носителями того или иного языка на основании степени владения нормой данного (родного или иностранного) языка. Акцент как результат интерференции артикуляционной базы родного языка является точкой сбоя аутентичности в устной речи на иностранном языке, и выраженность акцента детерминирует, таким образом, перемещение по шкале «свой/чужой» в языковой идентификации.

Изучение звуковой оболочки слова как фактора лингвистической идентичности стало возможным в рамках данного исследования на основе дедуктивного анализа, а также посредством наблюдения процесса освоения произносительной нормы немецкого языка русскоязычными обучающимися вуза.

При освоении немецкого языка как иностранного носители русского языка сохраняют в своей речи элементы акцента в связи с отличиями артикуляционных баз названных языков, основанными на различии в работе речевого аппарата, а также вследствие традиций адаптации заимствований из немецкого языка в русский.

Основными типами фонетической адаптации при заимствовании из немецкого языка в русский являются артикуляционная и звуковая адаптации, качественная и количественная звуковая замена, замена ударения. Эти традиции фонетической адаптации заимствований влияют на процессы освоения фонетических моделей немецкого языка на уровне фонетического слова, при этом элементы интерференции сохраняются тем дольше, чем меньше звуковая оболочка соответствует материальному (буквенному) воплощению языковой единицы.

Многоязычие является основной культурно-языковой моделью в контексте межкультурной коммуникации, поэтому понятие интерференции в языковом (коллективном) сознании и речевом (индивидуальном) поведении нуждается в междисциплинарном изучении. В качестве перспектив дальнейшего исследования можно обозначить разработку методики коррекции акцента с опорой на анализ традиций заимствований, а также анализ маркеров акцента с точки зрения шкалирования лингвистической идентичности на фонетическом уровне.

\section{Финансирование}

Публикация подготовлена при поддержке Фонда перспективных научных исследований ФГБОУ ВО «Челябинский государственный университет», 2021 г.

\section{Список источников}

1. Багана Ж., Хапилина Е. В. Акцент и ошибки как проявление интерференции // Вестник Воронежского государственного университета. 2006. Вып. 1. С. 55-58.

2. Будник Е. А. Фонетическая интерференция и иностранный акцент при обучении русскому языку как иностранному // Lingua mobilis. 2012. № 3 (36). С. 171-179.

3. Вишневская Г. М. Билингвизм и межкультурная коммуникация // Вестник Ивановского государственного университета. 2001. Вып. 1. С. 67-76.

4. Герман Н. Ф. Лингвокультурная идентичность субъекта коммуникации // Вестник Челябинского государственного университета. Серия «Философия. Социология. Культурология». 2009. Вып. 11 (149). С. 63-66.

5. Ефимова Р. М. Немецкие заимствования в русском языке [Электронный ресурс]. URL: https://pglu.ru/upload/ iblock/199/uch_2009_iii_00044.pdf (дата обращения: 12.01.2021).

6. Исканиус С. Языковая идентичность русскоязычной молодежи-иммигрантов в Финляндии // Социолингвистика. 2006. № 3. С. 314-328.

7. Красных В. В. Лингвокультурная идентичность Ноmo Loquens // Мир русского слова. 2007. № 4. С. 11-15.

8. Лаппо М. А. Сущность идентичности и методы ее анализа в лингвистических/психолингвистических исследованиях // Вопросы психолингвистики. 2014. № 1 (19). С. 30-39. 
9. Марцинковская Т. Д., Солодникова И. В. Трансформации социокультурной и лингвистической идентичности в процессе социализации в мультикультурной среде [Электронный ресурс]. URL: http://psystudy.ru/ index.php/num/2018v11n58/1550-martsinkovskaya58.html (дата обращения: 16.01.2021).

10. Николаев А. И. Иноязычный акцент как результат интерференции языковых систем // Филологические науки. Вопросы теории и практики. 2016. № 6 (60). Ч. 3. С. 119-121.

11. Перепечкина С. Е. Иноязычный акцент: проблема интерференции или вопрос самоидентификации? // Иностранная филология. Социальная и национальная вариативность языка и литературы: материалы III Международного научного конгресса / под ред. Е. В. Полховской. Симферополь: Ариал, 2018. С. 154-158.

12. Тазеев Г. Г., Ахметзянова Г. Р., Филькова А. Ю. Некоторые вопросы фонологии, морфологии и системности языка в работе Н. В. Крушевского «Очерк науки о языке» // Вестник Волжского университета имени В. Н. Татищева. 2018. № 4. Т. 1. С. 138-143.

\section{Информация об авторах | Author information}

RU Жаркова Ульяна Анатольевна ${ }^{1}$, к. филол. н., доц.

1 Челябинский государственный университет

EN Zharkova Uliana Anatoljevna ${ }^{1}, \mathrm{PhD}$

${ }^{1}$ Chelyabinsk State University

1germancsu@gmail.com

\section{Информация о статье | About this article}

Дата поступления рукописи (received): 02.01.2021; опубликовано (published): 09.04.2021.

Ключевые слова (keywords): интерференция; фонетическая адаптация заимствований; лингвокультурная идентичность; interference; phonetic adaptation of borrowings; linguo-cultural identity. 